\title{
Coliformes em água de abastecimento de lojas fast-food da Região Metropolitana de Recife (PE, Brasil)
}

\author{
Coliforms in the water supply of fast-food chains in the \\ Metropolitan Region of Recife, in the state of Pernambuco (Brazil)
}

Maria Anunciada Leal Porto ${ }^{1}$ Amanda de Morais Oliveira ${ }^{2}$ Ana Elizabeth Cavalcante Fai ${ }^{3}$ Tânia Lúcia Montenegro Stamford ${ }^{4}$

${ }^{1}$ Hospital Oswaldo Cruz, Universidade de Pernambuco. Rua Arnóbio Marques 310, Santo Amaro. 50100-010 Recife PE.

lili.leal@gmail.com

${ }^{2}$ Departamento de

Tecnologia Rural,

Universidade Federal de

Pernambuco.

${ }^{3}$ Departamento de Ciências de Alimentos, Faculdade de Engenharia de Alimentos, Universidade Estadual de Campinas.

${ }^{4}$ Departamento de Nutrição, Universidade Federal de

Pernambuco.

\begin{abstract}
A guaranteed supply of clean drinking water in food outlets is a relevant subject for public health. The scope of this study was to assess the microbiological quality of 96 water samples of a network of fast-food stores in the city of Recife (state of Pernambuco, Brazil) and Metropolitan Area and to compare the results to the standards established by Brazilian Health Ministry decree $n^{\circ}$ 518/2004. Every month, a double sample from one of the faucets in the food preparation area of the eight stores investigated was analyzed, totaling 96 samples over one year. The analyses followed the established methodology of American Public Health Association (APHA), in order to conduct the Presence-Absence Test, considering the potability standard in pertinent legislation. Results revealed that $11.46 \%$ and $1.04 \%$ of samples contained water contaminated with total coliforms and thermotolerant coliforms, respectively. The quality of the water in the food establishments studied is thus a health hazard since a significant percentage of samples analyzed were inappropriate for human consumption in accordance with current legislation, which stipulates the absence of total coliforms and thermotolerant coliforms.
\end{abstract}

Key words Water, Fast-food, Total coliforms, Thermotolerant coliforms
Resumo A garantia do fornecimento de água potável nos serviços de alimentação é uma questão relevante para a saúde pública. Assim, o objetivo deste estudo foi avaliar a qualidade microbiológica da água destinada ao abastecimento de uma rede de lojas fast-food da cidade de Recife (PE) e Região Metropolitana e comparar os resultados aos padrões estabelecidos pela Portaria no 518/2004 do Ministério da Saúde. Mensalmente, foi analisada uma amostra proveniente de uma das torneiras da área de manipulação das oito lojas investigadas, perfazendo 96 amostras ao longo de um ano, todas coletadas em duplicata. As análises seguiram a metodologia estabelecida na American Public Health Association (APHA) para realização do ensaio presuntivo utilizando o Teste Presença-Ausência, considerando-se o padrão de potabilidade determinado na legislação pertinente. Os resultados revelaram que $11,46 \%$ de todas as amostras apresentaram água contaminada por coliformes totais e 1,04\% contaminação por coliformes termotolerantes. Conclui-se, portanto, que a qualidade da água disponível nos estabelecimentos produtores de alimentos estudados encontra-se em estado de alerta, uma vez que o percentual significativo das amostras analisadas mostrava-se impróprio para o consumo humano de acordo com a legislação vigente, a qual preconiza ausência de coliformes totais e termotolerantes.

Palavras-chave Água, Fast-food, Coliformes totais, Coliformes termotolerantes 


\section{Introdução}

A água é essencial em todos os segmentos da vida, sendo considerada um recurso insubstituível. A oferta para abastecimento tem sido apontada como um dos grandes problemas do século XXI, ressaltando-se que a abundância do elemento líquido causa uma falsa sensação de recurso inesgotável $^{1}$, pois $95,1 \%$ da água do planeta é salgada, e dos 4,9\% restantes, apenas $0,147 \%$ estão aptos para o consumo humano ${ }^{2}$, ressaltando-se que atualmente cerca de 1,4 bilhão de pessoas não têm acesso à água limpa ${ }^{3}$.

De acordo com a Organização Mundial da Saúde (OMS), cerca de 80\% de todas as doenças que acometem os países em desenvolvimento provêm de água de má qualidade ${ }^{4}$. As doenças de veiculação hídrica, como febre tifoide, cólera, salmonelose, shigelose, poliomielite, hepatite A, verminoses, amebíase e giardíase, são predominantemente resultantes do ciclo de contaminação fecal/oral e têm sido responsáveis por vários surtos epidêmicos, representando causa de elevada taxa de mortalidade em indivíduos com baixa resistência imunológica ${ }^{5-7}$.

Relatos de contaminação de água por bactérias do grupo coliformes são muito frequentes. Coliformes totais incluem espécies do gênero Klebsiella, Enterobacter e Citrobacter, sendo Escherichia coli a principal representante do subgrupo termotolerante ${ }^{8}$. Zulpo et al. ${ }^{9}$ afirmam que os coliformes totais são encontrados no solo e nos vegetais, possuindo a capacidade de se multiplicarem na água com relativa facilidade. No entanto, os termotolerantes não se multiplicam facilmente no ambiente externo e ocorrem constantemente na flora intestinal do homem e de animais de sangue quente, sendo capazes de sobreviver de modo semelhante às bactérias patogênicas, atuando, portanto, como potenciais indicadores de contaminação fecal e de patógenos entéricos em água fresca ${ }^{9}$.

Assim, o monitoramento das condições sanitárias de água para consumo (geralmente realizado por análises das bactérias do grupo coliforme $)^{10-12}$ deve ser realizado para obtenção de um controle efetivo, pois ações destinadas à estruturação da vigilância rotineira da qualidade da água são indispensáveis para determinar a segurança para o consumo, buscando a proteção à saúde pública ${ }^{13,14}$.

Considerando que a qualidade microbiológica da água é requisito essencial para a produção de alimentos seguros e que ainda há negligência por parte de muitos produtores de ali- mentos em relação à potabilidade deste recurso, o presente trabalho teve o objetivo de avaliar a qualidade microbiológica da água destinada ao abastecimento de uma rede de lojas fast-food situadas na cidade de Recife (PE) e Região Metropolitana e comparar os resultados obtidos aos padrões estabelecidos pela legislação vigente ${ }^{15}$.

\section{Material e métodos}

Foi realizada a verificação microbiológica da água, em termos qualitativos, quanto à presença ou ausência de coliformes totais e termotolerantes durante o ano de 2006, em oito lojas de uma rede de fast-food situadas no Recife e Região Metropolitana. A escolha da investigação nesta rede se deu pela sua expansão e baseada no alto índice de aceitação pelos consumidores, bem como na capacidade mercadológica para instalação de três modelos distintos de operação de loja: tradicional (atendimento em salão e drive-thru), fast (lojas de autoatendimento) e o sistema delivery.

As lojas 1, 2 e 3 localizavam-se em praças de alimentação de três shopping centers, com abastecimento de água de origem pública, sendo de responsabilidade dos shoppings o controle da potabilidade das águas e da higienização dos seus reservatórios. A loja 4 era localizada em região comercial de um bairro popular com abastecimento de água de origem pública e atendida pelo sistema de saneamento básico. Já a loja 5 dispunha de água proveniente de poço freático com bomba dosadora de cloro, localizada em um bairro predominantemente residencial (construções antigas e recentes) com elevada concentração populacional, além de ter grande atividade de construção civil e não possuir cobertura total de saneamento básico. Quanto à loja 6, esta também utilizava água de poço freático com bomba dosadora de cloro, estando localizada no sítio histórico em prédio predominantemente residencial de instalações muito antigas. As lojas 7 e 8 eram situadas em área residencial e comercial, dispunham de água de abastecimento público e também de poço freático com bomba dosadora de cloro, visando reduzir custos quanto aos recursos hídricos.

Mensalmente, foi analisada uma amostra proveniente de uma das torneiras da área de manipulação de cada loja, perfazendo um total de 96 amostras ao longo de um ano, que foram coletadas em duplicata para efeito de confirmação caso a primeira análise apresentasse contaminação. 
Antes da coleta da amostra, a torneira era previamente higienizada com solução de álcool $70 \%$ por meio de pulverização interna e externa. Em seguida era aberta, deixando-se escoar a água por um período de dois a três minutos, visando eliminar impurezas e água acumulada na canalização, sendo fechada em seguida.

A coleta era realizada pelo técnico do laboratório contratado, utilizando frascos de vidro previamente lavados e secos contendo $0,1 \mathrm{~mL}$ de tiossulfato de sódio $\left(\mathrm{Na}_{2} \mathrm{~S}_{2} \mathrm{O}_{3}\right)$ a $10 \%$ para cada $100 \mathrm{~mL}$ de água a ser coletada, os quais foram posteriormente esterilizados a $121^{\circ} \mathrm{C}$ por $21 \mathrm{mi}-$ nutos. No momento da coleta, a torneira e a boca do frasco de vidro eram flambadas, a torneira era aberta para coletar $100 \mathrm{ml}$ da amostra, em duplicata, em seguida o frasco contendo a amostra e reagente era novamente flambado, fechado imediatamente e identificado. Após a coleta, era realizado o teste de cloro residual, que para nenhuma das amostras estudadas apresentou irregularidade em relação à preconização da Portaria no 518/2004 do Ministério da Saúde ${ }^{15}$.

Para o transporte, as amostras foram acondicionadas em caixas isotérmicas contendo baterias de gelo conservador e encaminhadas ao laboratório contratado credenciado à Agência Nacional de Vigilância Sanitária, onde procederam-se as análises seguindo a metodologia descrita pelo APHA (Standard Methods for the Examination of Water and Wastewater $)^{16}$. Para realização da pesquisa de coliformes totais, todas as amostras foram submetidas a um ensaio presuntivo utilizando-se o Teste Presença-Ausência (PA), sendo que cada $100 \mathrm{~mL}$ de amostras foram colocados nos frascos contendo $50 \mathrm{~mL}$ de caldo PA triplo com tubos de Durhan invertidos. Após a inoculação, as amostras foram incubadas a $35^{\circ}$ $\mathrm{C} \pm 0,5^{\circ} \mathrm{C}$ por $24 / 48$ horas. As amostras que apresentaram reação presuntiva positiva (mudança de coloração do meio de púrpura para amarelo e produção de gás) foram submetidas a teste confirmatório para coliformes totais em caldo lactose verde brilhante bile (CLVBB) 2\%. As amostras que evidenciaram formação de gás em CLVBB foram inoculadas em tubos de ensaio contendo $10 \mathrm{~mL}$ de caldo EC e incubadas em banhomaria a $44,5^{\circ} \mathrm{C} \pm 0,2^{\circ} \mathrm{C}$ por $24 / 48$ horas. Esta última etapa teve por objetivo a pesquisa de coliformes termotolerantes.

Para observar se o risco de contaminação microbiológica presente na água poderia contaminar os alimentos produzidos, em nenhuma das lojas onde as análises foram realizadas houve a observação da qualidade de água na entrada dos prédios, visto que as torneiras eram previamente higienizadas antes da coleta da água.

\section{Resultados e discussão}

Os resultados revelaram que $12,50 \%$ das amostras coletadas estavam em desacordo ao preconizado pela Portaria no 518/2004 do Ministério da Saúde ${ }^{15}$ em relação ao padrão microbiológico de coliformes totais e termotolerantes (Gráfico 1).

Estudos realizados pelo Instituto Tecnológico do Estado de Pernambuco para avaliar a potabilidade e traçar um perfil higiênico-sanitário da água consumida em residências, empresas e hospitais da cidade do Recife mostraram que, nas empresas, apenas 36\% foram consideradas satisfatórias. Os maiores índices de contaminação foram de bactérias do grupo coliformes totais (64\%), seguido de Pseudomonas aeruginosa (33\%), coliformes fecais $(25 \%)$ e Staphylococcus aureus (13\%). Em mais de 50\% das amostras de residências, foi identificada contaminação pelo grupo coliforme, não sendo possível uma comparação com registro de anos anteriores devido à inexistência de dados divulgados em Pernambuco ${ }^{17}$.

Recentemente, Feitosa Neto et al. ${ }^{14}$ analisaram a qualidade sanitária da água de bebedouro de 35 escolas públicas do Recife, verificando que $37 \%$ apresentavam-se em desacordo com os padrões de potabilidade legais brasileiros. Em estudo semelhante, Zulpo et al. ${ }^{9}$ avaliaram a qualidade microbiológica da água de 47 bebedouros da Universidade Estadual do Centro-Oeste, revelando que $8,5 \%$ e $2 \%$ amostras apresentaram positividade para coliformes totais e termotole-

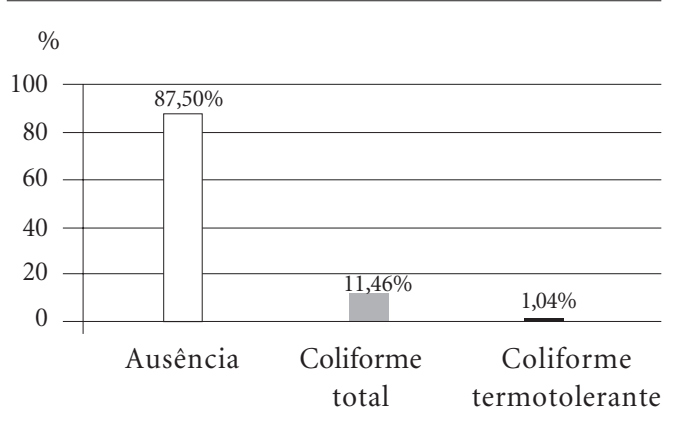

Gráfico 1. Percentual de contaminação de água de consumo em 96 amostras de uma rede de fast-food situada no Recife (PE) e Região Metropolitana durante o ano de 2006. 
rantes, respectivamente, contrariando os termos dispostos na legislação para água de consumo.

A presença de coliformes totais (Gráfico 2) constatada nas águas de consumo das lojas estudadas ressalta a importância desse grupo de bactérias como indicador de precárias condições higiênico-sanitárias. A ocorrência desse grupo microbiano em águas dá subsídios à discussão sobre falhas no sistema de tratamento de água ou distribuição, uma vez que esses microrganismos podem ser encontrados em diversos ambientes naturais, mas não na água potável ${ }^{18}$.

De acordo com o Gráfico 2, pode-se observar que os estabelecimentos 3 e 6 apresentaram contaminações mais frequentes durante todo o ano, enfatizando-se que estes estavam localizados em um dos bairros mais antigos da cidade, constituinte do sítio histórico do Recife, caracterizado por área residencial e comercial, de intensa concentração populacional e saneamento deficitário com predominância de fossas sépticas.

Em relação à loja 3, apesar de o estabelecimento ter sua água proveniente de abastecimento público, sua localização deve ser levada em consideração quanto ao nível de contaminação, pois existe uma grande possibilidade de rupturas das canalizações públicas decorrentes do processo de corrosão do ferro, material comumente utilizado em tubulações construídas há mais de cinquenta anos $^{19}$, possibilitando a ocorrência de infiltrações de esgotamentos sanitários nos sistemas de abastecimento de água potável da região.

A loja 6, por sua vez, fazia uso de água proveniente de poço freático e, apesar de utilizar bomba dosadora de cloro, em $41,66 \%$ e $8,33 \%$ das

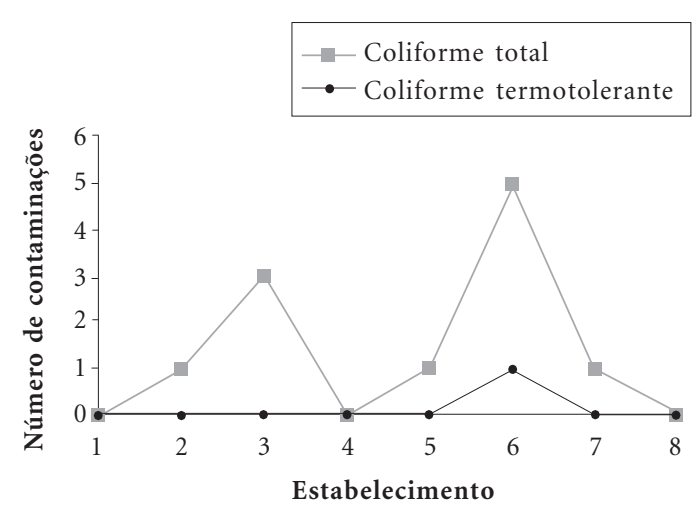

Gráfico 2. Frequência de contaminação da água de consumo, distribuída por estabelecimento, de uma rede de fast-food situada no Recife (PE) e Região Metropolitana, 2006. amostras analisadas deste estabelecimento evidenciou-se a presença de coliformes totais e termotolerantes, respectivamente (Gráfico 2). Este fato pode ser justificado pela grande possibilidade de contaminação devido à concentração de fossas sépticas na região ou pela água da chuva que, ao percolar o solo, arrasta consigo substâncias dissolvidas que podem ser rapidamente conduzidas ao lençol freático. Vale ressaltar que a presença de Escherichia coli na água é considerada indicativa de contaminação fecal recente, já que esta bactéria encontra dificuldades para se multiplicar fora das condições entéricas ${ }^{18,20}$.

Segundo Silva et al. ${ }^{21}$, a água subterrânea tem se tornado uma fonte alternativa de abastecimento de água para o consumo humano. Isto é devido tanto à escassez quanto à poluição das águas superficiais, tornando os custos de tratamento, em níveis de potabilidade, cada vez mais elevados. Em geral, as águas subterrâneas são potáveis e dispensam tratamento prévio, pois os processos de filtração e depuração do subsolo promovem a purificação da água durante a sua percolação no meio, tornando-se uma fonte potencial de água de boa qualidade e baixo custo, podendo sua exploração ser realizada em áreas rurais e urbanas. No entanto, as fontes de contaminação antropogênicas em águas subterrâneas são em geral diretamente associadas a despejos domésticos, industriais e ao chorume oriundo de aterros de lixo que contaminam os lençóis freáticos com microrganismos patogênicos ${ }^{5}$.

Como pode ser visualizado no Gráfico 3, durante o período de racionamento de água (dezembro, janeiro e fevereiro) implantado na cidade de Recife, percebe-se o maior índice de contaminação das águas de consumo das lojas estudadas, principalmente em fevereiro, quando $38 \%$ dos estabelecimentos apresentaram água contaminada por coliforme total. Cabe ressaltar que, nos estabelecimentos que faziam uso apenas de água de abastecimento público, durante o período de escassez a aquisição de água por empresas de fornecimento através de "caminhão pipa" só acontecia mediante a comprovação da potabilidade.

Macedo ${ }^{4}$ e Freitas et al. ${ }^{5}$ afirmam que a irregularidade do abastecimento na rede de uma área urbana pode também modificar a qualidade da água tratada com a introdução de agentes patogênicos na rede de distribuição.

As características da água a ser tratada têm influência marcante no processo de desinfecção. Quando o agente desinfetante é um oxidante, a presença de material orgânico e outros compostos oxidáveis irão consumir parte da quantidade 


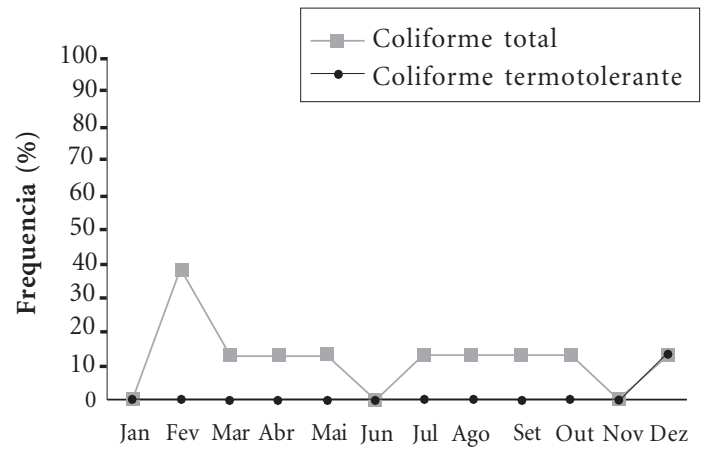

Gráfico 3. Frequência de contaminação da água de consumo, distribuída por mês, de uma rede de fastfood situada no Recife (PE) e Região Metropolitana, 2006.

de desinfetante necessária para destruir os organismos. O uso de cloro no tratamento da água pode ter como objetivos a desinfecção, a oxidação ou ambas as ações ao mesmo tempo, sendo a desinfecção o objetivo principal e mais comum da cloração $0^{22}$.

Segundo $\mathrm{Macedo}^{4}$, a qualidade final da água tratada depende fundamentalmente das características do manancial que a fornece, pois alguns contaminantes dificilmente são removidos nesse processo, evidenciando a limitação do atual sistema convencional de tratamento de água para abastecimento público. Contudo, não se pode garantir que água aduzida pelo abastecimento público não sofra mudanças no ramal interno consumidor, fazendo com que a qualidade da água na torneira se diferencie da que deixa a estação de tratamento ${ }^{13}$. Além disso, Freitas et al. ${ }^{5} \mathrm{e}$
Mattos e Silva ${ }^{8}$ afirmam que a perda de integridade desse sistema está diretamente relacionada a processo ineficaz de higienização e manutenção do reservatório.

Todos os estabelecimentos avaliados neste estudo efetuaram higienização periódica dos reservatórios de água durante o ano de 2006, executadas por empresas especializadas, seguindo as recomendações descritas na RDC no 216 do Ministério da Saúde do Brasil23.

Informações da literatura em associação aos dados obtidos neste estudo evidenciam a problemática da potabilidade da água, fator que favorece a alta incidência de doenças de veiculação hídrica. Além disso, sabe-se que ela é elemento fundamental na preparação de alimentos, fazendo-se necessário maior controle de qualidade da água utilizada em serviços de alimentação como medida preventiva da saúde pública.

\section{Conclusão}

Durante o ano de 2006, a água de consumo de oito estabelecimentos que compreendem uma rede de lojas fast-food situadas no Recife e Região Metropolitana apresentou água contaminada por coliforme total, sendo que uma das lojas apresentou também contaminação por coliforme termotolerante.

Controlar a potabilidade da água é imprescindível na garantia de produção de alimentos seguros, uma vez que a água desempenha papel fundamental neste segmento, sendo utilizada na formulação de produtos alimentícios, higienização de alimentos, instalações, utensílios, equipamentos, superfície de manipulação e manipulador, bem como na fabricação de gelo e vapor.

\section{Colaboradores}

MAL Porto trabalhou na coleta, análise e interpretação dos dados e redação do artigo; AM Oliveira, na análise e interpretação dos dados e redação; AEC Fai, na interpretação e redação do artigo; TLM Stamford, na revisão crítica e na aprovação da versão a ser publicada. 


\section{Referências}

1. Vendramel E, Köhler VB. A história do abastecimento de água em Maringá, Estado do Paraná. Acta Scientiarum 2002; 24(1):253-260.

2. Rainho JM. Planeta água. Rev Educ 1999; 26(221):4864.

3. Cunha AC, Cunha HFA, Brasil Júnior ACP, Daniel LA, Schulz HE. Qualidade microbiológica da água em rios de áreas urbanas e periurbanas no Baixo Amazonas: o caso do Amapá. Eng Sanit Ambient 2004; 9(4):322-328.

4. Macedo JAB. Águas e 'sguas. Juiz de Fora: Ortofarma; 2000.

5. Freitas MB, Brilhante OM, Almeida LM. Importância da análise de água para a saúde pública em duas regiões do Estado do Rio de Janeiro: enfoque para coliformes fecais, nitrato e alumínio. Cad Saude Publica 2001; 17(3):651-660.

6. Amaral LA, Nader Filho A, Rossi Júnior OD, Ferreira FLA, Barros LSS. Água de consumo humano como fator de risco à saúde em propriedades rurais. Rev Saude Publica 2003; 37(4):510-514.

7. Silva RCA, Araújo TM. Qualidade da água do manancial subterrâneo em áreas urbanas de Feira de Santana (BA). Cien Saude Colet 2003; 8(4):1010-1028.

8. Mattos MLT, Silva MD. Controle da qualidade microbiológica das águas de consumo na Microbacia $\mathrm{Hi}$ drográfica Arroio Passo do Pilão. Pelotas: Ministério da Agricultura, Pecuária e Abastecimento; 2002.

9. Zulpo DL, Peretti J, Ono LM, Garcia JL. Avaliação microbiológica da água consumida nos bebedouros da Universidade Estadual do Centro-Oeste, Guarapuava, Paraná, Brasil. C Agrárias 2006; 27(1):107110

10. Forsythe SJ. Microbiologia da segurança alimentar. Porto Alegre: Artmed; 2002.

11. Blanch AR, Galofré B, Lucenal F, Terradillos A Vilanoval X, Ribas F. Characterization of bacterial coliform occurrences in different zones of a drinking water distribution system. J Appl Microbiol 2007; 102:711-721.

12. Schwab KJ. Are existing bacterial indicators adequate for determining recreational water illness in waters impacted by nonpoint pollution? Epidemiol 2007; 18(1):21-22.

13. D’Aguila OS, Roque OCC, Miranda CAS, Ferreira AP. Avaliação da qualidade de água para abastecimento público do Município de Nova Iguaçu. Cad Saude Publica 2000; 16(3):791-798.

14. Feitosa Neto A, Silva JL, Moura GJB, Calazans GMT. Avaliação da qualidade da água potável de escolas públicas do Recife, PE. Hig Alim 2006; 20(139):8082.
15. Brasil. Ministério da Saúde. Portaria no 518/Brasília, de 25 de março de 2004. Estabelece os procedimentos e responsabilidades relativos ao controle e vigilância da qualidade da água para consumo humano e seu padrão de potabilidade, e dá outras providências. Diário Oficial da União 2004; 25 mar.

16. American Public Health Association (APHA). Standard methods for the examination of water and wastewater. $20^{\text {th }}$ ed. Washington, DC: American Water Works Association, Water Enviroment Federation; 1998.

17. Alves NC, Odorizzi AC, Goulart FC. Análise microbiológica de águas minerais e de água potável de abastecimento, Marília, SP. Rev Saude Publica 2002; 36(6):749-751.

18. Michelina AF, Bronharoa TM, Daréb F, Ponsanoc EHG. Qualidade microbiológica de águas de sistemas de abastecimento público na região de Araçatuba, SP. Hig Alim 2006; 20(147):90-95.

19. Oliveira ACS, Terra APS. Avaliação microbiológica das águas dos bebedouros do Campus I da Faculdade de Medicina do Triângulo Mineiro, em relação à presença de coliformes totais e fecais. Rev Soc Bras Med Trop 2004; 37(3):285-286.

20. Franco BDGM, Landgraf M. Microbiologia dos alimentos. São Paulo: Atheneu; 2002.

21. Silva RLB, Barra CM, Monteiro TCM, Brilhante OM. Estudo da contaminação de poços rasos por combustíveis orgânicos e possíveis conseqüências para a saúde pública no Município de Itaguaí, Rio de Janeiro, Brasil. Cad Saude Publica 2002; 18(6): 1599-1607.

22. Macedo JAB. O processo de desinfecção pelo uso de derivados clorados em função do $\mathrm{pH}$ e a Portaria 518/2004 do Ministério da Saúde. In: Anais do XLIV Congresso Brasileiro de Química. Fortaleza; 2004.

23. Brasil. Ministério da Saúde. Portaria no 216/Brasília, de 15 de setembro de 2004. Regulamento Técnico sobre Condições Higiênico-Sanitárias e de Boas Práticas para Serviços de Alimentação. Diário Oficial da União 2004; 15 set.

Artigo apresentado em 01/10/2007

Aprovado em 29/05/2008

Versão final apresentada em 06/08/2008 